\title{
Chapter 5 \\ An Optimization Model for Technology Adoption of Marginalized Smallholders
}

\author{
Deden Dinar Iskandar and Franz W. Gatzweiler
}

\begin{abstract}
The rural poor are marginalized and restricted from access to markets, public services and information, mainly due to poor connections to transport and communication infrastructure. Despite these unfavorable conditions, agricultural technology investments are believed to unleash unused human and natural capital potentials and eleviate poverty through productivity growth in agriculture. Based on the concept of marginality, we develop a theoretical model which shows that these expectations for productivity growth are conditional on human and natural capital stocks and transaction costs. Policy recommendations for segment and location specific investments are provided. Theoretical findings indicate that adjusting rural infrastructure and institutions to reduce transaction costs is a more preferable investment strategy than adjusting agricultural technologies to marginalized production conditions.
\end{abstract}

Keywords Marginality - Infrastructure • Productivity growth • Human capital • Transaction costs

\section{Background}

This paper seeks to provide the theoretical support for interventions to increase the income-generating capacity of the rural farm households below the poverty line. In particular, we observe the impact of technology adoption and the transaction cost effects on the income generation capacity in specific segments of the rural poor. There is a role for agricultural technology innovations in influencing the poor directly by lifting constraints and increasing the output level of on-farm production (Irz et al. 2001). An empirical study from Mendola (2007) also emphasizes the potential role of technology in reducing poverty through the improvement of smallholders' production capacity.

In contrast to the economics of organization in which transaction costs are defined as costs which occur "... when a good or service is transferred across a

D.D. Iskandar $(\triangle)$ • F.W. Gatzweiler

Center for Development Research (ZEF), University of Bonn, Bonn, Germany

e-mail: deden.dinar@gmail.com; gatzweiler@gmail.com 
technologically separable interface." (Williamson 1985, p. 1), this paper defines transaction costs as the costs that create barriers between rural households and input and output markets, and restrict market access, communication and interaction.

These costs mainly include transportation costs, due to the lack of wellmaintained roads, long distances between the rural households and the market, and lack of affordable public transport facilities. Transaction costs also arise from the poor communication infrastructure for accessing and exchanging information regarding markets, products, and prices.

According to Reardon et al. (2001), insufficient access to public infrastructure raises entry barriers to more profitable labor markets. Renkow et al. (2004) examine the magnitude of fixed transaction costs that hamper the access to markets for subsistence farmers in Kenya. They predict that the impact of high transaction costs on the farmers' income is equal to a tax of $15 \%$. Therefore, the impact of infrastructure investment on farmers' welfare is equivalent to cutting a tax of identical size. A study by Stifel and Minten (2008) on transaction costs and poverty in Madagascar finds that the incidence of rural poverty increases with increasing remoteness, and the yields of major crops and the utilization of agricultural production inputs fall significantly with the distance to the market.

Our study categorizes the rural farm households below the poverty line into four segments (Fig. 5.1) according to labor and land endowments within the marginality framework of von Braun and Gatzweiler (2014). The households in the first segment are characterized by relatively higher labor capacity and land productivity. The households in the second segment feature higher land productivity, but lower labor capacity, while, contrastingly, the households in the fourth segment possess lower land productivity and higher labor capacity. The third segment represents the households under extreme poverty, with both low land productivity and low labor capacity. In this study, these extremely poor households will be referred to as the households under the survival line, since their main concern is to fulfill their basic needs for survival.

\section{Theoretical Analysis}

\section{The Optimization Problem for Rural Households Under the Poverty Line}

The income for a rural farm household is generated from the revenue of agricultural production (on-farm activities) and the revenue of renting out factor inputs, mainly labor, to off-farm activities. The rural farm household below the poverty line is assumed to depend on two primary inputs for agricultural production: land and labor. In addition to these main inputs, farm production also requires farming production input, such as farming equipment, fertilizer and seeds. We assume that the objective of the household is to maximize total household production 


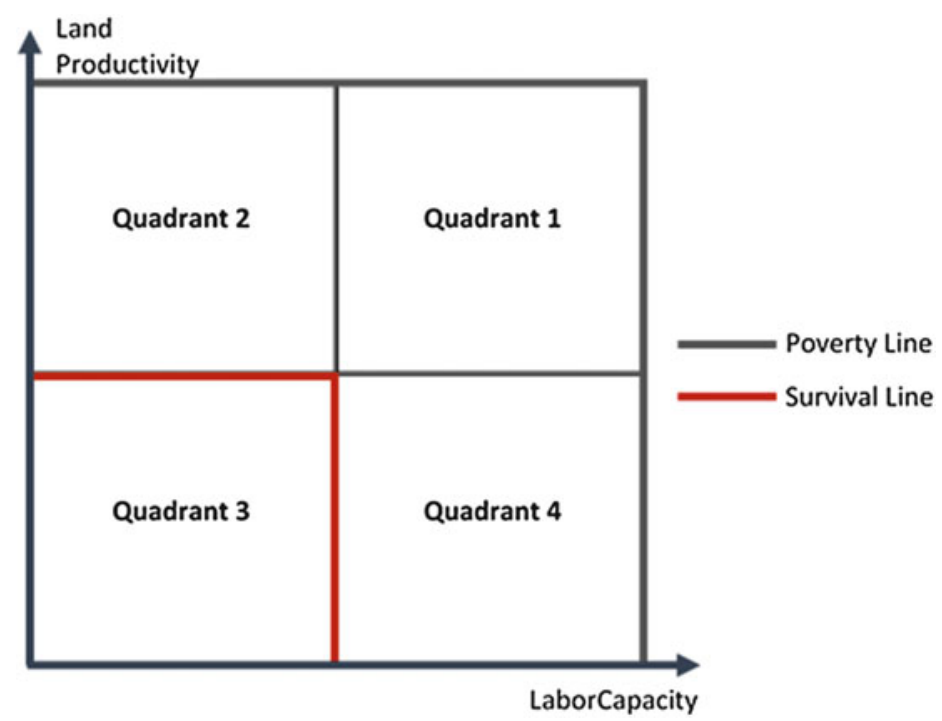

Fig. 5.1 The segmentation of rural farm households based on land and labor endowment

from on- and off-farm activities. After the introduction of technology, the objective function of a rural household is formulated in the following equation:

$$
\begin{gathered}
\underset{X, \hat{X}, \tilde{X}, V}{\operatorname{Max}}\left(\frac{1}{T}\left((p . Y)+\sum_{i=1}^{n}\left(\hat{w}_{i} \cdot \hat{X}_{i}\right)\right)-T \cdot\left(\sum_{i=1}^{n}\left(\widetilde{w}_{i} \cdot \widetilde{X}_{i}\right)+\sum_{j=1}^{m}\left(c_{j} \cdot V_{j}\right)\right)\right) \\
\text { S.t. } \sum_{i=1}^{n}\left(X_{i}+\hat{X}_{i}\right) \leq \sum_{i=1}^{n}\left(\bar{X}_{i}+\widetilde{X}_{i}\right) \\
T \cdot\left(\sum_{i=1}^{n}\left(\widetilde{w}_{i} \cdot \widetilde{X}_{i}\right)+\sum_{j=1}^{m}\left(c_{j} \cdot V_{j}\right)\right) \leq B_{i}
\end{gathered}
$$

where

$$
Y=\prod_{i=1}^{n}\left(X_{i}^{\alpha_{i}}\right) \cdot \prod_{j=1}^{m}\left(V_{j}^{\beta_{j}}\right)
$$

The income from on-farm activities is depicted by $(p . . Y)$, where $Y$ stands for the aggregate output of farm activities and $p$ is the respective market price. Farm production is formulated as a Cobb-Douglas production function. Production output is determined by the production inputs $\left(X_{i}\right)$, where $i$ represents different types of input. Each input has a different elasticity, $\alpha_{i}$, that represents the percentage of change in agricultural production output resulting from a $1 \%$ change in the input $i$. 
The technology adopted also contributes to farm production. The technology used in the production process is indicated by $V_{j}$, where $j$ refers to different types of technology. The productivity output elasticity of each technology, $\beta_{i}$, indicates the percentage change of farm output arising from a $1 \%$ change in the adoption of technology $j$. The production function is further characterized by $\left(\partial Y / \partial X^{\alpha}>0\right)$ and $\left(\partial Y / \partial V^{\beta}>0\right)$, meaning that production will increase with production input and adopted technology. The revenue generated from off-farm activities is formulated as $\left(\hat{w}_{i} \cdot \hat{X}_{i}\right)$, where $\left(\hat{w}_{i}\right)$ and $\left(\hat{X}_{i}\right)$ represent the price and the volume of input $i$ used for other productive activities outside the farm household.

The total revenue of on-farm and off-farm activities should be adjusted by the transaction costs, $T$. The transaction costs occur because of spatial marginality and exclusion, specifically the difficulty of accessing the market because of the lack of public infrastructure and access to market information. The actual revenue will be discounted by transaction costs, since a certain proportion of household income needs to be spent to reach the market for selling farm output and buying the household's production input.

The costs of generating the household income can be divided into production costs and the costs of technology adoption. The production costs, $\left(\widetilde{w}_{i} \cdot \widetilde{X}_{i}\right)$, indicate the costs of production inputs that are not available in the household. $\widetilde{X}_{i}$ indicates the input $i$ imported from outside the household, with $\widetilde{w}_{i}$ as its respective price. The cost of adopting technology is formulated as $\left(c_{j} \cdot V_{j}\right)$, where $c_{j}$ is the price to adopt technology $j$. The presence of transaction costs $(T)$ will increase the technology adoption costs, since the household has additional expenditures for reaching the input or technology market.

Equation (5.2) indicates the resource constraint faced by the household. The input $i$ used for on-farm activities $\left(X_{i}\right)$ and off-farm activities $\left(\hat{X}_{i}\right)$ is limited by the availability of the total input $i$, which is composed of the household's input endowment $\left(\bar{X}_{i}\right)$ and the input rented in from outside the household $\left(\widetilde{X}_{i}\right)$. Equation (5.3) is the budget constraint confronted by the household, which indicates that the total costs of employing additional inputs and adopting technology should not exceed the available production budget $(B)$.

Given the input and budget constraints, the rural household maximizes the total income by deciding on the optimal amount of choice variables. Those variables include the amount of production input used for on-farm activities $\left(X_{i}\right)$, the amount of input used for off-farm activities $\left(\hat{X}_{i}\right)$, the amount of additional input to be hired from outside the household $\left(\widetilde{X}_{i}\right)$, and the extent of adopted technology to be used for on-farm activities $\left(V_{j}\right)$.

The following Lagrangean equation formulates the maximum income function for the household under the specified input and budget constraints: 


$$
\begin{aligned}
L= & \frac{1}{T}\left((p \cdot Y)+\sum_{i=1}^{n}\left(\hat{w}_{i} \cdot \hat{X}_{i}\right)\right)-T \cdot\left(\sum_{i=1}^{n}\left(\widetilde{w}_{i} \cdot \widetilde{X}_{i}\right)+\sum_{j=1}^{m}\left(c_{j} \cdot V_{j}\right)\right) \\
& +\lambda_{1}\left(\left(\bar{X}_{i}+\widetilde{X}_{i}\right)-\left(X_{i}+\hat{X}_{i}\right)\right)+\lambda_{2}\left(B_{i}-T \cdot\left(\sum_{i=1}^{n}\left(\widetilde{w}_{i} \cdot \widetilde{X}_{i}\right)+\sum_{j=1}^{m}\left(c_{j} \cdot V_{j}\right)\right)\right) .
\end{aligned}
$$

The Lagrange multipliers in Eq. (5.5), $\lambda_{1}$ and $\lambda_{2}$, measure the infinitesimal change in the generated income resulting from infinitesimal changes in the constraints. In the constrained optimization, $\lambda_{1}$ and $\lambda_{2}$ could be interpreted as marginal losses in the generated income due to the reduction in the availability of inputs and budget, respectively. These multipliers could also be interpreted differently as the marginal income of the increase in the available inputs and household budget.

Taking the first derivative of the Lagrangean equation will give the marginal income of each choice variable, i.e., change in the income generated by one unit change in the choice variable.

$$
\begin{gathered}
\frac{\partial L}{\partial X_{i}}=\frac{1}{T} \cdot\left(\frac{p \cdot \alpha_{i} \cdot V_{j}^{\beta_{j}}}{X_{i}^{\left(1-\alpha_{i}\right)}} \cdot\right)-\lambda_{1}, \\
\frac{\partial L}{\partial \hat{X}_{i}}=\frac{1}{T} \cdot \hat{w}_{i}-\lambda_{1}, \\
\frac{\partial L}{\partial V_{j}}=\frac{1}{T} \cdot\left(\frac{p \cdot X_{i}^{\alpha_{i}} \cdot \beta_{j}}{V_{j}^{\left(1-\beta_{j}\right)}}\right) \cdot-T \cdot c_{j} \cdot\left(1+\lambda_{2}\right), \\
\frac{\partial L}{\partial \widetilde{X}_{i}}=\lambda_{1}-\left(1+\lambda_{2}\right) \cdot T \cdot \widetilde{w}_{i} .
\end{gathered}
$$

Setting Eqs. (5.6), (5.7), (5.8) and (5.9) equal to zero will give the First Order Condition (FOC), the condition for the optimal level of each choice variable to maximize the income. Rearranging Eq. (5.6) equal to zero in terms of $\left(X_{i}\right)$ will give the condition for the optimal level of input $i$ as follows:

$$
X_{i}=\left(\frac{p \cdot \alpha_{i}}{T \cdot \lambda_{1}} \cdot V_{j}^{\beta_{j}}\right)^{\frac{1}{\left(1-\alpha_{i}\right)}}
$$

To generate the maximal income, the level of utilized input $i$ should be equal to the marginal income of the input and the extent of adopted technology, adjusted by the transaction cost and the marginal income loss by reducing the input availability $i$ to the identical size as the employed input. The marginal income is determined by $\left(p \cdot \alpha_{i}\right)$, the product of output price and input $i$ elasticity. This optimal condition implies that the utilization of input $i$ in on-farm activities will increase with the output price and the input elasticity $i$, and decrease with the transaction costs and the marginal costs of losing the input availability to the same amount as the utilized input. 
Equation (5.10) suggests that the optimal allocation of the inputs towards on-farm activities is determined by their elasticities. The higher the input elasticity, the more intensive the respective input could be used in production. Let $L d$ stand for land and $L b$ represent labor. The households in segment 2 with relatively higher land productivity, but lower labor capacity, $\alpha_{L d}>\alpha_{L b}$, will make use of land more intensively. On the other hand, the households in segment 4 with relatively lower land productivity, but higher labor capacity, $\alpha_{L d}<\alpha_{L b}$, will rely more on the utilization of labor to generate income from agricultural production. In segment 1 , in which households have equally higher levels of land productivity and labor capacity, and in segment 3 , in which the households suffer from equally low levels of land productivity and labor capacity, the contribution of labor and land utilization to the generated income is evenly balanced, $\alpha_{L d}=\alpha_{L b}$.

$$
\frac{X_{L d}}{\left(p \cdot \alpha_{L d}\right)^{\frac{1}{\left(1-\alpha_{L d}\right)}}}=\frac{X_{L b}}{\left(p \cdot \alpha_{L b}\right)^{\frac{1}{\left(1-\alpha_{L b}\right)}}} .
$$

The optimal condition for the allocation of those two inputs ( $L d$ and $L b$ ) on agricultural production is depicted in Eq. (5.11). When the households use two inputs, they will exhaustively use one particular input that gives the highest return (i.e., the input with higher elasticity) up to the point that the ratio of utilized input and the resulting marginal income between the two inputs is equal.

We can infer from Eqs. (5.10) and (5.11) that the presence of transaction costs, $T$, will reduce the optimal production input. Transaction costs discount the revenue from agricultural production. When the transaction costs increase, the optimal input for use in farm production will also decrease, since the actual revenue generated from the utilization of input is declining.

The condition for the optimal level of exported input for off-farm activities is given by the following equation:

$$
\frac{1}{T} \cdot \hat{w}_{i}=\lambda_{1}
$$

The level of input used for off-farm activities will be optimal if the marginal revenue, which is the price of the input $i$ adjusted by transaction cost, is equal to the marginal loss of generated income due to the reduction of input $i$ availability. If the marginal revenue earned from off-farm activities is higher than the marginal loss, the optimal choice for farm households is to keep renting out the inputs. On the other hand, if the marginal loss is higher than the expected marginal revenue from renting out the inputs, then the rational household will keep the inputs for on-farm activities. In the presence of a transaction cost, the revenue from off-farm activities will be discounted, since the household will have additional costs to reach the input market.

Combining Eqs. (5.11) and (5.12) will link the decisions concerning allocation of the input between on-farm and off-farm activities. 


$$
X_{i}=\left(\frac{p \cdot \alpha_{i} \cdot V_{j}^{\beta_{j}}}{\hat{w}}\right)^{\frac{1}{\left(1-\alpha_{i}\right)}} .
$$

Equation (5.13) indicates that increasing wages for off-farm work will decrease the allocation of input $i$ to on-farm activities. Assuming that the transaction costs affects both the optimal input for use in on-farm and off-farm activities at the same scale, the transaction cost will not influence the decision.

The optimal level of technology adoption is then depicted by the following equation:

$$
V_{j}=\left(\frac{p \cdot \beta_{j}}{T^{2} \cdot c_{j} \cdot\left(1+\lambda_{2}\right)} \cdot X_{i}^{\alpha_{i}}\right)^{\frac{1}{\left(1-\beta_{j}\right)}} .
$$

Equation (5.14) says that the level of adopted technology $j,\left(V_{j}\right)$, will be optimal if it is equalized to the marginal income of the adopted technology adjusted by the transaction cost and marginal income loss due to reducing the budget at hand. The marginal income is formulated as the product of output price and the elasticity of adopted technology on the generated income $\left(p \cdot \beta_{j}\right)$. The optimal level of adopted technology will increase with the output price and the elasticity of technology $j$, and decrease with the cost of obtaining the technology.

The contribution of technology to income generation does not work in isolation, but is a joint action in which the utilization of production inputs also takes part. Therefore, the condition for optimal adoption of technology is also influenced by the elasticity of input $i, \propto_{t}$. The optimal level of technology adoption and its contribution to income generation will increase (decrease) with a higher (lower) elasticity of the input production.

Equation (5.14) also indicates that the presence of transaction costs will reduce the optimal level of technology adoption at a multifold scale. Transaction costs hinder the adoption of technology in two ways: by discounting the actual revenue of production output and increasing the actual cost of acquiring the technology. Therefore, when the transaction costs and the price of technology are higher, it will be a rational option for rural households to decrease the adopted level of technology.

$$
T \cdot \widetilde{w}_{i}=\frac{\lambda_{1}}{\left(1+\lambda_{2}\right)} .
$$

Equation (5.15) demonstrates the optimal condition for employing additional input production from outside households. In this equation, $\lambda_{1}$ represents the marginal income from increasing the available input. The optimal level of additional input $i$ will depend on the costs of acquiring the input $i$, the marginal income of increasing the availability of input $i$, and the marginal costs of losing the available budget. The households will start buying additional input $i$ when the marginal income from 
increasing the input adjusted by the marginal cost of decreasing the current availability of the budget ${ }^{1}$ (as a consequence of the payment made to buy the input) are higher than the price of input $i\left(\widetilde{w}_{i}\right)$ adjusted by the transaction cost.

\section{The Optimization Problem for Rural Households Under the Survival Line}

The extreme poor and marginalized rural households exist under worse conditions. In our model, their capacities are constrained to fulfilling basic survival needs. The budget constraint they live under restricts them from adopting agricultural technologies or buying additional inputs to increase production. Therefore, the constraints in Eqs. (5.2) and (5.3) are changed into the following equations:

$$
\begin{gathered}
X_{i}+\hat{X}_{i} \leq \bar{X}_{i}, \\
B p \leq \dot{T}\left(\left(\widetilde{w}_{i} \cdot \widetilde{X}_{i}\right)+\left(c_{i} \cdot V_{i}\right)\right) .
\end{gathered}
$$

$\dot{T}$ is the transaction cost confronted by the poorest households. We can expect transaction costs to be higher for those households which are more marginalized, therefore $\dot{T}>T$. Under the new constraints, the objective function for extremely poor smallholders is the following:

$$
\underset{X, \hat{X}}{\operatorname{Max}} \sum_{i=1}^{n}\left(\frac{1}{\dot{T}}\left((p \cdot Y)+\left(\hat{w}_{i} \cdot \hat{X}_{i}\right)\right)\right) .
$$

From the equation above, it is obvious that the one option available to the very poorest households is limited to choosing the level of inputs to use in on-farm activities and renting out their labor for off-farm activities. The problem of optimal input allocation for generating maximal income is different from the problem of the rural households in other segments, and is formulated by the following Lagrangean equation:

$$
L=\frac{1}{\dot{T}}\left(\left(p \cdot Y_{i}\right)+\left(\hat{w}_{i} \cdot \hat{X}_{i}\right)\right)+\lambda_{1}((\bar{X}-\hat{X})-X) .
$$

The first derivation of Eq. (5.19) results in the marginal income of each choice variable,

\footnotetext{
${ }^{1}$ Spending the input for off-farm activities will reduce the available input at hand. This particular concept of cost covers the possibility that this reduction will create cost for the farmer's income generation.
} 


$$
\begin{gathered}
\frac{\partial L}{\partial X_{i}}=\frac{1}{\dot{T}} \cdot\left(\frac{p \cdot \alpha_{i}}{X_{i}^{\left(1-\alpha_{i}\right)}} \cdot\right)-\lambda_{1}, \\
\frac{\partial L}{\partial \hat{X}_{i}}=\frac{1}{\dot{T}} \cdot \hat{w}_{i}-\lambda_{1} .
\end{gathered}
$$

While the marginal income of renting out labor input for off-farm activities is theoretically identical (Eqs. (5.7) and (5.21) are exactly the same), it can be deduced from Eq. (5.20) that, as the extreme poor have fewer available inputs, the marginal income from input utilization for the poorest households is lower than that of the other households. That is reasonable, since the poorest households have not adopted (modern) technology in their agricultural production, whereas the production output is a joint result of all input utilization in interaction.

The conditions for the optimal level of input allocated for on-farm and off-farm activities are given in the following equations:

$$
\begin{gathered}
X_{i}=\left(\frac{p \cdot \alpha_{i}}{\dot{T} \cdot \lambda_{1}}\right)^{\frac{1}{\left(1-\alpha_{i}\right)}}, \\
\frac{1}{\dot{T}} \cdot \hat{w}_{i}=\lambda_{1} .
\end{gathered}
$$

Equation (5.22) suggests that the optimal input used in on-farm activities will increase with output price and input elasticity, and decrease with transaction cost and the marginal cost of increasing input availability. This optimization behavior is equal to that of the less poor households, however, due to the absence of technological adoption, the optimal level of input utilization will be lower than the optimal level of the less poor households.

The decision to rent out the input for off-farm activities is identical to the other households (Eqs. (5.12) and (5.23) are identical). It depends on wages, transaction costs, and marginal income loss by reducing the current availability of input to spend outside the households. If the wage, after being adjusted by transaction costs, is higher than the marginal income loss for accessing labor markets, then the households will keep renting out the input up to the point where the wage and the marginal loss are equal.

Combining Eqs. (5.22) and (5.23) will link the decisions about allocating the input between on-farm and off-farm activities.

$$
X_{i}=\left(\frac{p \cdot \alpha_{i}}{\hat{w}}\right)^{\frac{1}{\left(1-\alpha_{i}\right)}} .
$$

Equation (5.24) indicates that the increase in revenue by renting out input $i$ to off-farm activities $(\hat{w})$ will decrease the utilization of input $i$ for agricultural production on-farm. The amount of inputs $i$ that the poorest households intend to keep for on-farm activities is lower than that of the less poor households. Since the marginal income of the input $i$ is lower, the poorest households are willing to rent out more input (labor) to generate household income. 


\section{Theoretical Support for Government Intervention}

From the theoretical analysis, we can infer that the income generation capacity of rural households below the poverty line is determined by input elasticities, technology adoption level, and transaction costs. Particularly for the very poorest households, special attention should be given to increasing their available household budget so as to enable them to adopt productivity-increasing technologies to an extent that they would rather invest their labor on-farm than renting it out. Increasing the income of poor rural households requires the improvement of input elasticities and technology adoption, the reduction of transaction costs, and budget injection for extremely poor households. For many of the poorest households, an improvement in income elasticity and technology adoption could be a result of improving rural infrastructures, market access and land rights, which would also reduce transaction costs and improve proximity. However, if improving proximity by adjusting rural infrastructure and reducing marginality is perceived as too costly, a likely alternative for many rural poor will be to migrate to less marginal areas with better proximity and better access to markets.

\section{Budget Injection for Extremely Poor Rural Households}

The extremely poor households are suffering from a lack of budgetary capacity to support their production beyond survival levels. Therefore, one option for increasing their income-generating capacity is cash transfers from the government. Cash transfers have a direct increasing impact on the households' budget availability, moving the budget constraint from Eq. (5.3) to Eq. (5.17).

However, for the transfer to have a more permanent impact on sustainable income generation, cash transfers need to be large enough to cover the household's basic consumption needs, so that the rest of the cash transfer may be used for agricultural production, buying farming tools and seeds, and acquiring technology. An example can be found in the 2005 cash transfer program in Zambia, which shows that $29 \%$ of the received cash transfer in the Kalomo district was invested in either livestock or agricultural inputs after the consumption of basic needs was satisfied (MCDSS and GTZ 2005).

\section{The Improvement of Technology Adoption}

We can see from Eq. (5.14) that the level of technology adoption is deterred by the availability and cost of obtaining the respective technology. The availability of technology and the cost of adoption could be defined as the function of government expenditure on research and development. 


$$
\begin{aligned}
V_{j} & =f\left(\dot{G}_{j}\right), \\
c_{j} & =f\left(\dot{G}_{j}\right) .
\end{aligned}
$$

$\dot{G}_{j}$ is the government expenditure on research and development of agricultural technology $j . V_{j}$ represents the technology $j$ available for adoption by rural farm households, with $c_{j}$ as its respective price. The availability of technology $j$ is characterized by $\partial V_{j} / \partial \dot{G}_{j}>0$, indicating that the availability of technology increases as the government increases spending on research and development. On the other hand, the cost of the adoption of technology $j$ is featured with $\partial c_{j} / \partial \dot{G}_{j}<0$, meaning that the cost decreases with government expenditure on research and development. If the government provides the subsidy for producing technology, the availability of technology will increase at a lower price and the level of adoption will increase.

However, the financial capacity of households to acquire the available technology will be different between poor households living adjacent to the poverty line and those who are extremely poor and living adjacent to or under the survival line. Therefore, besides cash transfers, cheaper technology needs to be made available to facilitate its adoption by the extremely poor households.

\section{Improvement in Input Elasticities}

Productivity improvements can also be achieved by improving input elasticity. Elasticity of input $i$ is assumed to be the function of government investment $I_{i}$, which, in turn, is determined by government spending on that particular program, $\ddot{G}_{i}$.

$$
\begin{gathered}
\alpha_{i}=f\left(I_{i}\right), \\
I_{i}=g\left(\ddot{G}_{i}\right) .
\end{gathered}
$$

Equations (5.27) and (5.28) are characterized by $\left(\partial \alpha_{i} / \partial I_{i}\right) \cdot\left(\partial I_{i} / \partial \ddot{G}_{i}\right)>0$, indicating that the elasticity of input $i$ will increase with government spending . For instance, to increase the elasticity of land, the corresponding government program could be the provision of a better fertilizer funded by the government. Aside from directly providing the fertilizer, the government could also support a program to help the households make their own fertilizer. For example, the practical training program conducted by the United Nations Development Programme (UNDP) in Northern Nigeria provides practical guidance on how to make compost heaps and green manure for fertilizer (Onyemaobi 2012). The program now successfully yields better harvests for the rural households.

On the other hand, the increase in labor elasticity could be facilitated through the provision of training supported by the government. The role of the households' 
labor in agricultural production is not only limited to providing the work-force to cultivate the crops, but also acting as decision-makers and applying good agricultural practice. To succeed in farming, rural households need more training beyond basic literacy. They need training regarding the right crops to plant, the type and quantity of required inputs, and the methods for utilizing limited resources with greater efficiency. Better skill and knowledge will lead to higher return on labor employment in agricultural production.

Another example is a training program conducted by the UNDP in Northern Nigeria providing a practical demonstration on better farming techniques (Onyemaobi 2012). Other examples for increasing the farming skill of rural households are the farmer field schools. The season-long programs enable the farmers to meet regularly and learn new agricultural techniques. According to Davis et al. (2010), the farmer field schools have resulted in important improvements in farmer productivity. In particular, this approach is beneficial for poor farmers with a low level of primary education.

To produce effective results, the program should be targeted to address the right problems. For example, the households with lower land productivity call for provision of better and safer fertilizer. On the other hand, the households with relatively lower labor capacity require practical training to increase their skills and knowledge. These ways, the optimal condition, as indicated by Eq. (5.11), could be reached. Improving the education and skill of the farmer does not only enhance labor elasticity, but also increases technology absorption capacity. More educated and skilled smallholders will have a better capacity to adopt specific technologies and make use of them for accelerating income generation.

\section{Reduction of Transaction Costs}

Transaction costs result from the lack of public physical and institutional infrastructure and are a barrier to accessing the market. The difficulty in accessing the market impedes the opportunities to generate income. It reduces the market opportunity for agricultural products, decreases the returns to labor and land of on-farm activities, and increases the input costs, as well as the costs of adopting technology. It also reduces the opportunity of rural households to participate in labor markets for off-farm activities. Transaction cost, $T$, can be formulated as the function of government expenditure on public infrastructure, $\bar{G}$,

$$
T=f(\bar{G}) .
$$

The equation above is characterized by $\partial T / \partial \bar{G}<0$, meaning that transaction costs will decrease with increasing government spending on public infrastructure. In the case of the poor households under the survival line, Eq. (5.29) is slightly modified into $\dot{T}=f(\bar{G})$, where $\dot{T}>T$. 
Increasing the provision of public infrastructure will increase the actual revenue of agricultural production and off-farm activities, as well as lessen the cost of production, thus enhancing opportunities for generating income from agriculture. Public investment in transportation and communication infrastructure are particularly important as attempts to reduce transaction costs.

Access to public infrastructure leads to a reduction in those transaction costs, which the poor rural households have to carry when they access the output and input markets. Lower transaction costs could change the structure of relative prices for the poor farmer. This change will enable poor households to earn higher revenue from agricultural production and lower production cost, thus increasing their income. Lower transaction costs also allow the poor farm households to acquire the necessary additional inputs and technology; hence, they encourage the improvement in agricultural production that leads to higher agricultural output.

Finally, lower transaction costs may induce a change in the allocation of labor input between on-farm and off-farm activities. When rural households commit to more than one income-generating activity, the access to public infrastructure will influence the households' labor allocation decisions. The reduction in transaction cost due to the availability of public infrastructure will increase opportunities for poor rural households to participate in off-farm activities. On the other hand, lower transaction costs and improved public infrastructure, and the subsequent proximity and access to markets, may change labor allocation decisions to on-farm activities.

\section{Conclusions}

The theoretical optimization model for decision-making of marginalized smallholders on which we have elaborated assumes rational decision-makers. The likelihood of poor and extremely poor smallholders making decisions as elaborated in this optimization model correlate directly to the extent that these smallholders act rationally. This study provides theoretical evidence for increasing the income generation capacity of rural farm households below the poverty line by means of government interventions linked to the agricultural production process, like conditional cash transfers and improvements in institutional infrastructure. Particular concern should be given to the reduction of transaction costs, since high transaction costs reduce the revenue from on-farm as well as off-farm activities and increase the cost of using additional production inputs and adopting innovative technologies. Technology adoption, which has been advocated as one of the most promising ways to enhance the agricultural production capacity of the poor, is not as effective for productivity growth under the presence of high transaction costs. That is particularly relevant to marginalized smallholders. The provision of public infrastructure and improved institutions would lead to a reduction in transaction cost and increase income opportunities for poor rural households.

Segmentation of poor households provides differentiated recommendations for intervention strategies. For instance, the extremely poor households living under 
the survival line need more provision of infrastructure to overcome access barriers and cheaper technology than the poor households adjacent to the poverty line. Investments to increase input productivity also varies between different segments. Assuming that the households are rational, they will use those productive inputs which promise the highest return on income and thereby intensify production. Therefore, the government should invest to increase input productivity, so that their income generation capacity is increased.

Investments in technology in segments of rural society in which there is insufficient absorption capacity reduces the returns on technology investment, even if the technology is adjusted to the specific agro-ecological conditions. Productivity growth cannot be achieved in those segments, because the depreciation of human and social capital is larger than the investments in said capital. Improving the institutional infrastructure and reducing transaction costs by improving education and information and securing property rights would decrease societal depreciation, improve absorption capacities and make investments in technological innovations economically worthwhile.

From a broader agricultural development perspective, there is a trade-off between adjusting agricultural technologies to the marginalized production conditions of poor and extremely poor segments of rural society versus adjusting rural infrastructure and institutions to allow for the economically effective use of agricultural technologies. Theoretical findings indicate that adjusting rural infrastructure and institutions to reduce transaction cost is more preferable. However, it has become obvious that institutional and technological innovations need to go hand-inhand. Therefore, both strategies need to be further informed by a spatially-specific approach.

Given the overall goal of productivity growth in agriculture, areas in which agricultural infrastructure is fragmented and marginalized will require investment in adjusting the technology to the locality. If these investments are not made, rural populations will most likely move to urban areas and both human and agroecological potentials will be lost. In areas in which agricultural infrastructure is less fragmented and marginalized, the use of agricultural technology which allows for the grasping of scale effects is economically advisable.

Open Access This chapter is distributed under the terms of the Creative Commons AttributionNoncommercial 2.5 License (http://creativecommons.org/licenses/by-nc/2.5/) which permits any noncommercial use, distribution, and reproduction in any medium, provided the original author(s) and source are credited.

The images or other third party material in this chapter are included in the work's Creative Commons license, unless indicated otherwise in the credit line; if such material is not included in the work's Creative Commons license and the respective action is not permitted by statutory regulation, users will need to obtain permission from the license holder to duplicate, adapt or reproduce the material. 


\section{References}

Davis K, Nkonya E, Kato E, Mekonnen DA, Odendo M, Miiro R, Nkuba J (2010) Impact of farmer field schools on agricultural productivity and poverty in East Africa. International Food Policy Research Institute, Washington, DC

Irz X, Thirtle C, Lin L, Wiggins S (2001) Agricultural productivity growth and poverty alleviation. Dev Policy Rev 19(4):449-466

MCDSS and GTZ (2005) External monitoring and evaluation report of the pilot social cash transfer scheme, Kalomo District, Zambia. Ministry of Community Development and Social Services and German Technical Cooperation, Lusaka

Mendola M (2007) Agricultural technology adoption and poverty reduction: a propensity-score matching analysis for rural Bangladesh. Food Policy 32(3):372-393. doi:10.1016/j.foodpol. 2006.07.003

Onyemaobi K (2012) In Nigeria, farm training yields fuller harvests for rural women. Available from: http://www.undp.org/content/undp/en/home/ourwork/environmentandenergy/ successstories/in-nigeria--farm-training-yields-fuller-harvests-for-rural-women/. Accessed 2 Feb 2014

Reardon T, Berdegué J, Escobar G (2001) Rural nonfarm employment and incomes in Latin America: overview and policy implications. World Dev 29(3):395-409. doi:10.1016/S0305750X(00)00112-1

Renkow M, Hallstrom DG, Karanja DD (2004) Rural infrastructure, transactions costs and market participation in Kenya. J Dev Econ 73(1):349-367. doi:10.1016/j.jdeveco.2003.02.003

Stifel D, Minten B (2008) Isolation and agricultural productivity. Agric Econ 39(1):1-15. doi:10. 1111/j.1574-0862.2008.00310.x

von Braun J, Gatzweiler FW (2014) Marginality. Addressing the nexus of poverty, exclusion and ecology. Springer, Dordrecht/Heidelberg/New York/London

Williamson OE (1985) The economic institutions of capitalism. The Free Press, New York 